Israeli universities

\section{Faculty forced into salary cut}

Rehovot

WHEN every occupational group in Israel is wildly scrambling for wage increases, Israeli professors and senior lecturers have agreed to a 6 per cent cut in wages. "We took the step", says Professor Menachem Magidor, chairman of the Coordinating Council of Faculty Organizations, "in order to prevent a generation of young scientists from being wiped out."

Behind the melodramatic language lies the brutal fact that Israeli institutions of higher learning, now in the midst of a severe and prolonged financial crisis, have had to dismiss more than $\mathbf{2 0 0}$ members of their academic staffs over the past year and will have to dismiss more unless some solution to their budgetary problem is found.

The 6 per cent pay cut in itself is significant only insofar as it may prod the government into increasing its support for the universities. Indeed, shortly after the professors made their statement, the government said it would cover some of the $\$ 50$ million debt accumulated by institutions of higher learning. But a pledge made shortly before election day may have little relevance after polling has taken place.

Nobody doubts, in any case, that Israeli universities and research centres are in trouble and that standards are falling. In the recent report of the planning and grants committee of the Council for Higher Education, its chairman, Professor Haim Harari, pointed out that during the past decade the student body of local universities has risen by 30 per cent while the teaching staff has fallen by 3 per cent, and that there are serious problems with equipment and facilities.

"What is at stake", Harari declared, "is not merely the future of higher education and scientific research but the future of Israel itself. Israel has no chance of developing and prospering if it is not in the front ranks of science and culture."

The sophistication of Israel's industry and agriculture, he says, reflects the achievements of Israeli institutions of higher learning 10 or 15 years ago. Today, in contrast, "the people we will need in the 1990 s are being trained in far inferior conditions". And there is a great difference between a young scientist who gets personal attention from his teachers, and who uses advanced equipment, and one who is trained at a university where the equipment is old and in poor repair, and where the ratio between students and teachers is more appropriate for a high school than for a university.

Research is also hampered by financial constraints, even where it has clear economic importance. One researcher working in the field of artificial intelligence has pointed out that people at Massachusetts Institute of Technology working on artificial intelligence and related subjects have at their disposal about 50 VAX computers and 50 others, while he has only one of each.

This situation is not likely to encourage other young Israelis, now holding top positions in the United States, to come home. Some now working at such places as IBM, Bell Laboratories and Harvard University have recently made it clear that they would be ready to return immediately if only they could be assured of the equipment they need to carry out their experiments. But the money simply is not available.

Some researchers find themselves in another kind of Catch-22 situation. A leading Israeli expert on applied physics has been offered more research grants than he can possibly handle. But his institution has put a freeze on hiring, and institutional salaries are, in any case, so much lower than those offered by industry that he is unlikely to find qualified engineers and technicians for his research teams.

Most institutions of higher learning have tried to solve their problems by cost cutting, but the Haifa Technion has adopted the opposite approach. Its international board of governors has decided to ignore the 10 per cent cut urged by the government and to increase its budget for the next academic year by $\$ 4$ million so as to purchase new equipment and to hire 165 junior faculty members for its computer sciences, aeronautical engineering, industrial engineering and mechanical engineering faculties which, it says, should be enlarged to meet the country's needs.

The Technion obviously hopes that the government, impressed by the need to train manpower for science-based industry, will give it more money, even if this means giving less to other institutions. It remains to be seen whether this hope has any basis in reality.

\section{Rows continue over US patent life}

\section{Washington}

BIOTECHNOLOGY companies are complaining that they have been left in the lurch by a compromise between two major camps of pharmaceutical companies on extending the life of patents.

The major research-intensive drug companies have for years been asking Congress to "restore" to their patents the time lost in meeting government safety-test requirements. According to the Pharmaceutical Manufacturers Association, 8.5 years of the 17-year life of a patent is lost in carrying out the required tests and obtaining approval from the Food and Drug Administration (FDA) to market new drugs.

Legislation that would extend patents to compensate for regulatory delays has met stiff opposition from another group of drug companies, the so-called "generic" manufacturers whose principal business is making Brand $X$ versions of patented drugs after the original patent expires. The generic versions are always considerably cheaper than their brand-name competitors, a fact that has never pleased the traditional companies. The generic companies maintain that the public interest is best served, however, by encouraging open competition as soon as possible.

Under the recently agreed compromise, now before Congress (HR 3605), the traditional companies would get their patent extension (one-half the time they spend testing plus all of the time FDA spends processing the application - up to a maximum of five years' extension); in return, the generic companies would be permitted to file "Abbreviated New Drug Applications"' (ANDA) for their lookalike drugs.

These applications would permit the generic manufacturer to use the safety and effectiveness data already submitted to
FDA by the original manufacturer. Under the present rules, generic manufacturers must duplicate those tests unless they have been published in the open literature. FDA officials have said for some time that they consider this to be a wasteful process, and one that results in unnecessary clinical trials on humans.

A much more controversial provision of the compromise allows the generic companies to jump the gun - to begin testing the original manufacturer's drug even before the original patent expires, so as to be in a position to hit the streets as soon as the patent expires. (The present law forbids any commercial use by a competitor until the patent expires.) The proposal would also allow a generic company (or anyone else) to challenge the validity of a drug patent at any time simply by filing an abbreviated new drug application for the same product.

Ronald Cape, chairman of Cetus, testified before a House of Representatives subcommittee last month that the compromise - while perfectly sensible for major drug companies that have a continual stream of new products going onto the market - would inadvertently harm the emerging biotechnology industry. The prospect of extended patent life means relatively little to the biotechnology companies - which are only now getting their first patents - and hardly compensates for the prospect of immediate harassment that the ANDA challenges may bring. "A very large portion of our resources could be tied up fighting these ANDAs", he said, which would encourage "premature litigation" - especially harmful to a young field such as biotechnology which has not even had the benefit of judicial determinations of the validity and scope of its patents. Stephen Budiansky 